УДК 170.2

DOI 10.18413/2712-746X-2020-45-1-158-163

\title{
ФИЛОСОФСКО-АНТРОПОЛОГИЧЕСКИЙ АНАЛИЗ ПЕРФОРМАНСА В ИСТОРИИ ЕВРОПЕЙСКОЙ ЦИВИЛИЗАЦИИ
}

\section{PHILOSOPHICAL-ANTHROPOLOGICAL ANALYSIS OF PERFORMANCE IN THE HISTORY OF EUROPEAN CIVILIZATION}

\author{
Н.В. Бараниченко \\ N.V. Baranichenko \\ Белгородский государственный институт искусств и культуры \\ Россия, Белгород, 308033, Королёва ул., 7 \\ Belgorod State Institute of Arts and Culture \\ 7 Koroleva St, Belgorod, 308033, Russia \\ E-mail: fin@bgiik.ru
}

\begin{abstract}
Аннотация
Реконструированы философско-антропологические смыслы перформанса в европейской культуре, основанные на имманентным противоречии между событием и игрой. Отмечается, что перформанс зарождается как игра, связанная с подражанием и мимикрией. Древнегреческий театр возникает на основе обрядовых игр и создает основу перформанса - связь игры и события. Избыточная жизненность игры в соединении с трансформирующим свойством события обусловили граничное положение актеров среди средневековых сообществ. В эпоху модерна перформанс погружен в социально-политическую и социально-экономическую систему координат, а в актуальном состоянии перформанс можно охарактеризовать через обращение к самому себе.
\end{abstract}

\begin{abstract}
The article reconstructed the philosophical and anthropological meanings of performance in European culture, based on the immanent contradiction between the event and the game. It is noted that performance is born as a game associated with imitation and mimicry. The ancient Greek theater arises on the basis of ritual games and creates the basis of performance - the connection of the game and the event. The excessive vitality of the game, combined with the transforming property of the event, determined the boundary position of the actors among medieval communities. In the modern era, the performance is immersed in the socio-political and socio-economic coordinate system, and in the current state, the performance can be characterized by referring to oneself.
\end{abstract}

Ключевые слова: игра, перформанс, европейская культура, театр, актер.

Key words: game, performance, european culture, theater, actor.

Современная философская антропология и философия культуры не часто обращают внимание на конкретные виды искусства. Традиционно они попадают в дисциплинарное поле эстетики, истории искусства, искусствоведения и культурологии. Вместе с тем часто занимая значимое место в культурной жизни города, являясь инициатором множества резонансных событий, театр ускользает от философской рефлексии. Погружение «в глубь» антропологии театра раскрывает междисциплинарное пространство серьезных академических проблем институционализации сообществ, онтологии события, труда, свободы, актуальные вопросы осмысления постмодернизма, субкультур, визуального, игры в 
различных её интерпретациях и вариантах бытования, а также позволяет выявить ускользающий объект - актера и актерское сообщество, достаточно закрытое, занимающееся специфической деятельностью, говорящее на особом языке, сохраняющее собственную, давнюю мифологию. Подобная закрытость и автономность актёрских сообществ тем более удивительна на фоне эксплозивного роста кинематографа и феномена массмедиа. Размывание границ приватного мира зрителя и актерского сообщества, на первый взгляд, не оставляет неизученных и незримых территорий, подобных театру. Актеры охотно сами показывают свою профессиональную и частную жизнь. В этом контексте антропология театральной субкультуры является более чем актуальной и важной для осмысления современной культуры, самого актерского сообщества, понимания «режимов видимости» в тотально видимой современной культуре.

Под артистической субкультурой мы понимаем профессиональное сообщество людей, главной целью которого является производство перформанса (осуществление перформативных практик) как вида творческой художественно-игровой деятельности. Главный отличительный признак артистической субкультуры - наличие коллективного игрового перформанса и потребность в зрителе (воспринимающем субъекте). Мы также рассматриваем артистическую субкультуру как культурно-исторический феномен, в основе которого лежит перформанс реализующийся в ткани истории в перформативных практиках, имеющих свою историческую и культурную специфику.

К родовым понятиям перформанса можно отнести прежде всего игру. Феномен игры достаточно изучен в ранней истории человечества и соотносится с потребностями самоидентификации, принадлежности группе, реализации творческого начала, попытке контролировать эмоции. Зарождение первобытного искусства часто связывают с игрой как перевоплощением, с помощью которого древний человек пытался влиять на негативные явления окружающего мира, общаться с магическими силами.

Н.Э. Микеладзе отмечает, что европейская средневековая культура характеризовалась коммуникативностью, а общество, разделённое на сословия, пользовалось вертикально-горизонтальной коммуникативной структурой с преимуществом вертикали. Искусство позволяло эту вертикаль преодолеть. Автор пишет: «Вертикаль становится проницаемой и ломается в таких сферах средневековой жизни, как жизнь религиозная, средневековый карнавал и связанные с ним смеховые и пародийные жанры, а также общедоступный массовый театр» [Микеладзе, 2006, с. 32]. Театр в Англии служил распространению знаний о мире, новостей, информировал об исторических событиях. Так, в Ренессансной Англии вспыхивает интерес к прошлому, и в исторических пьесах В. Шекспира видится выполненный социальный заказ (об этом упоминали несколько отечественных исследователей).

Н.Э. Микеладзе продолжает: «Риторический топос о мире, который является театром, содержит в себе, допускает и даже провоцирует многозначительную инверсию: следовательно, и театр есть не что иное, как мир. Так представляла себе современный мир английская королева Елизавета, когда утверждала: "Мы, государи, выведены на подмостки на обозрение всему миру". Так воспринимал значение театра английский драматург Уильям Шекспир, когда называл свой театр "Земным шаром" (Globe)» [Микеладзе, 2006, c. 32]. Н.Э. Микеладзе пишет о том, что по мнению С. Гринблата, «в основе самой власти королевы лежал театральный эффект сопричастности»: «Как в театре аудитория мощно вовлекается в происходящее за счет видимого присутствия героя на сцене, сохраняя одновременно определенную уважительную дистанцию, так и власть Елизаветы держалась на ее привилегии постоянного (театрализованного во многом) присутствия и видимости (privileged visibility) для подданных» [Микеладзе, 2006, с. 32].

Соглашаясь с тем, что театр всегда нёс в себе, по крайней мере, две функции коммуникативную и развлекательную, автор утверждает, что эти функции не были на 
равном положении в разные времена, и одна брала вверх над другой [Микеладзе, 2006, c. 32]. Театральные труппы елизаветинского времени вынуждены были искать себе покровителей, что и заставляло их обращаться к правящим кругам, людям, близким двору.

Например, В. Шекспир «с 1594 по 1613 год был постоянным членом труппы лорда Камергера, с 1603 года удостоенной титула "слуг его величества"» [История западноевропейского театра, 1981, с. 424]. Это обращение было выражено как в просьбах, так и в творчестве (иногда в завуалированной и льстивой форме). Театр обращался к власти, а человек на сцене, «оборачивался» в её сторону. У монарха в этом периоде европейской истории возникает возможность получить, как бы мы сейчас сказали, общественную поддержку посредством искусства, присутствия своей персоны на театральных представлениях. Постепенно и широко начинает использоваться приём аллегории, когда монаршая особа выводилась в тексте пьесы в виде античной богини или бога. Так, уже более поздние попытки Петра I обустроить в России театр в период абсолютизма, включали представления с аллегорическим изображением самого императора. Завуалировано со сцены шёл призывы к реформам, демонстрировался блеск военных побед, подтверждающие и утверждающие всю политику императора.

Б.Н. Асеев приводит следующие сведения: «...уже в одном из первых представлений московского школьного театра - "Страшное изображение второго пришествия господня на землю" (1702) - наряду с аллегорическими изображениями Церкви, Милосердия, Гордыни и Ярости появился "торжествующий Марс роксоланский", олицетворяющий Петра и Россию, "до него же Фортуна и Победа пришедшие, знамения победы тому вручают"» [Асеев, 1977, с. 131]. Народная драма «Царь Максимилиан» перекликалась с историческими событиями - конфликтом Петра I и царевича Алексея [Асеев, 1977, с. 136], закончившегося трагично. Коронационные торжества Екатерины II включали аллегорическое действие в форме маскарада «Торжествующая Минерва» [Асеев, 1977, с. 247], где под видом древнеримской богини мудрости была изображена просвещённейшая императрица). Император, царь, монарх заменяют в пьесах собой фигуры святых, богов, размещаясь в центре сюжета.

Театр приобретает особое значение в период Великой французской революции - в нём бушуют страсти и споры, а представители публики часто вступает в серьёзный конфликт друг с другом. Можно сказать, что столкновение двух миров французского общества того времени существовало не только в пространстве социального и политического, но и в пространстве воображаемого и театрального. О творчестве представителя революционного классицизма М.Ж. Шенье и его трагедии «Карл IX, или урок королям», Дантон сказал так: «если "Фигаро" (пьеса П.О. Бомарше - прим. Н.В.) убил дворянство, то "Карл IX" убьёт королевскую власть» [Французский театр, 1957, с. 63].

Г.Н. Бояджиев пишет, что в период Французской буржуазной революции в театрах шли классические пьесы Корнеля, Расина, Мольера со значительными изменениями, «...которых требовал политический момент, - из пьес изымалось употребление феодально-аристократических титулов: вместо "мосье" и "мадам" говорилось "гражданин" и "гражданка" и т.д.... «Тартюф» заканчивался тем, что представитель революционной власти арестовывал лицемера со словами "Прошло то время, когда низкий клеветник мог распоряжаться жизнью настоящих патриотов. Следуйте за мной!" [История зарубежного театра, 1972, с. 20].

Европейский театр переживает, по сути, момент нового рождения в период Просвещения. Создаются новые сюжеты, профессионализм актёров постепенно растёт, открываются учебные заведения, подготавливающие исполнителей. Драматурги Ж.-Б. Мольер, Ф.М.А. Вольтер и П.О. Бомарше в своих произведениях представляют уже не развлекательные традиции, а воспитывающие общество идеи, остро-социально звучащие темы и повороты сюжетов. Гражданский пафос звучал в русском театре в 1812 году, когда на фоне исторических событий создавались и представлялись публике как специальные 
постановки (патриотические балеты), так и интерпретированные публикой по-новому известные сюжеты.

Перформанс служил обществу и войне. Неслучайно, Наполеон Бонапарт, вступив в Москву, озадачил своих подданных распоряжением создать для своих войск театр, хотя бы из оставшихся в столице французских актёров. Интересно, что по сведениям М.И. Пыляева, французские актёры, отступая из России вместе с солдатами наполеоновской армии, испытали множество бед и несчастий, а одна из актрис, несмотря на своё бедственное положение, взяла на воспитание русскую девочку. Впоследствии этот благородный случай стал сюжетом драмы Э. Скриба «Ольга, русская сирота» (Пыляев).

В Санкт-Петербурге во время 1812 года ставились пьесы с сюжетами из русской истории «Пожарский», «Дмитрий Донской». А.К. Нарышкин писал: «...когда в последней пьесе вестник, вбегая на сцену, восклицал: "Россия спасена!" - театр стонал от избытка душевных потрясений. Тогда особенно сочувствовали пьесе Висковатого "Ополчение" и присоединенному к ней балету Кавоса под названием "Любовь к Отечеству". В балете одно появление знамени, с надписью: "За отечество", также доводило зрителей до громкого, одушевлённого восторга: кто плакал, кто кричал: "Браво, ура!", кто рукоплескал, одни вскакивали с мест своих, другие бросали на сцену кошельки с деньгами, крича: «"В пользу ополченцев, в пользу раненых!" Эти представления давали сряду несколько раз; многие после того спешили в комитет записываться в ополчение» (Нарышкин). В этот же период времени театральный перформанс удачно приобретает черты и функции карикатуры, политической сатиры.

П.П. Свиньин писал: «В Лондоне победы над французами доставили тамошнему Дрюриленскому театру много удачных представлений; Бонапарте в них являлся обыкновенно карликом, в арлекинском костюме, в ботфортах, с длинной косой и в высокой треугольной шляпе. Во всей Англии, в лубочных театрах, на ярмарках, для забавы черни выводили Наполеона на сцену по несколько раз и заставляли его карикатурно плясать. Иногда, забывая, что на сцене дурачится один из их единоземцев, а не сам Бонапарт, зрители бросали в него гнилыми яблоками. "Мы так много пьём за здоровье русских, - говорили англичане, - что у нас скоро вздорожает вино"».

И.Ф. Яцковская указывает: «В этот период укрепляется в своих правах буржуазный класс, возникают такие духовные ориентиры, как развитие личности, свобода, саморефлексия, капитал, благополучие. За рубежом танец модерн развивался в течение относительно короткого периода времени, его развитие в XX веке совпало с крупными историческими событиями (Первой и Второй мировыми войнами)...» [Яцковская, 2014].

Схожие культурные трансформации, искания и эксперименты происходят и в драматическом театре, но происходят они несколько позже. Подорванный войнами, растущим уровнем насилия, стремительным наступлением прогресса, ростом городов, индустриализацией и стремительной сменой ценностей, человек XX века стремился найти в себе новые духовные ресурсы, обращаясь к перформансу как к терапии искусством. Интересно, что в некоторых школах танца модерн присутствовала попытка придать движениям исполнителя подобие механичности, представить их похожими на автоматические движения машин и технических устройств; как будто сам исполнитель искал в себе машину, открывая новые стороны личности и возможности человека как «биомеханизма».

В Постмодерне театральный перформанс распространился далеко за театральные подмостки (представления устраиваются на заброшенных фабриках и заводах, на улицах, в лесу, на природе, в окружении древней архитектуры и т.д.). Парадоксальной ситуацией является то, что перформанс демонстрирует, что ему не нужен зритель, или по крайней мере, не важна зрительская реакция. Он репрезентирует, представляет без какой-либо конечной цели, без внимания на результат, без морального вывода в конце сюжета и остаётся без ясной концовки.

В театральных постановках режиссёров, ставящих постмодернистские эксперименты, можно увидеть и эпатаж, и попытку шокировать окружающих, использование непри- 
стойностей, отсутствие желания придерживаться общепринятой этики. Конечно, такая практика хоть и скандальна, но иногда может быть оправдана из-за большого воспитательного воздействия на социум. Анекдотичными случаями выступают некоторые «новаторские» постановки, либо глубоко непонятные зрителю, либо принимаемые в культурном вакууме мегаполисной жизни (когда практически не существует свободного времени, а следовательно, и незначителен опыт приобщения к настоящему профессиональному искусству).

Напомним, что в перформансе важен исполнитель. Но он «частично исчезает» в Постмодерне или обладает какими-либо изъянами. Профессионализм современного актёра может заключаться в том, что он не выглядит профессиональным либо одухотворённым. Исследователи культуры заговорили о телесности и новом феномене современного искусства - «теле-без-органов». Как утверждают источники, «идея тел-без-органов» впервые была обозначена А. Арто: «Тело есть тело, // оно одно, // ему нет нужды в органах...» [Новейший философский словарь]. Идея «тела-без-органов» встречается и у других авторов, например, у Ж. Делёза. Н.В. Курюмова, изучая современный танец, выявила самые разные модели телесности и пришла к следующим выводам: «Культурологический анализ классического танца, рассматриваемого в качестве оппозиционного современному танцу, позволяет выявить... модель телесности "идеальное тело". Культурологический анализ раннего модернистского (свободного) танца позволяет выявить модель телесности "телопорог". Культурологический анализ модернистского танца позволяет выявить... модели телесности: "тело-машина", "тело-симптом". Культурологический анализ танца постмодерн позволяет выявить... модели телесности: "повседневное тело", "феноменологическое тело", "тело-без-органов". Культурологический анализ так называемого "contemporary dance" позволяет выявить... модели телесности: "реальное тело" и "экстремальное тело"» [Курюмова, 2011]. Соответственно, исполнитель, дошедший до формы существования «тело», да ещё «тела без органов» существует не совсем так, как обычный человек, и диалог зрителя-человека с «телом» уже затруднителен.

\section{Список источников}

1. История западноевропейского театра. Т. І. 1981-1987. М., Просвещение, 471 с.

2. История зарубежного театра. Театр Европы и США XIX-XX вв. Ч. 2. 1972. М., Просвещение, 272.

3. История зарубежного театра. Театр Западной Европы. Ч. І. 1971. М., Просвещение, 360.

4. Тело без органов. Новейший философский словарь. Постмодернизм. URL: http://www.ereading.club/chapter.php/1027780/225/Gricanov___Noveyshiy_filosofskiy_slovar._Postmodernizm.html.

5. Тинина 3.П. 2005. История европейского театра от Античности до Новейшего времени. Ч. І. Античность. Средневековье. Возрождение: Учебно-методическое пособие. Волгоград, ВолГУ.: С. 11-12.

6. Французский театр эпохи Просвещения. Т.1. 1957. М., Искусство, 453 с.

7. Пыляев М.И. 2008. Наш театр в эпоху Отечественной войны. Старое житье. http://coollib.com/b/318896/read.

\section{Список литературы}

1. Асеев Б.Н. 1977. Русский драматический театр от его истоков до конца XVIII века. М., Искусство, 576 с.

2. Курюмова Н.В. 2011. Современный танец в культуре XX века: смена моделей телесности: диссертация ... кандидата культурологии: 24.00.01. Екатеринбург, 176 с.

3. Микеладзе Н.Э. 2006. О чем трубят театральные трубы? (Публичный театр как среда и средство коммуникации века Шекспира). Шекспировские чтения. 2004. М., Просвещение: С. 32-49.

4. Нарышкин А.К. Заметки о театре времён Отечественной войны 1812 года. URL: http://www.museum.ru/museum/1812/Library /Borodino_conf/2013/article43.pdf

5. Яцковская И.Ф. 2014.Этапы развития танца модерн и его стилевое разнообразие. Культура и образование. № 2. URL: http://vestnik-rzi.ru/2014/02/1395. 


\section{References}

1. Aseev B.N. 1977. Russkij dramaticheskij teatr ot ego istokov do konca XVIII veka. [Russian drama theater from its origins to the end of the XVIII century]. M., Iskusstvo, 576. (in Russian)

2. Kuryumova N.V. 2011. Sovremennyj tanec v kul'ture XX veka: smena modelej telesnosti: dissertaciya ... kandidata kul'turologii: 24.00.01 [Modern dance in the culture of the XX century: changing models of physicality: dissertation ... the candidate of cultural science: 24.00.01]. Ekaterinburg, 176 p. (in Russian)

3. Mikeladze N.E. 2006. O chem trubyat teatral'nye truby? (Publichnyj teatr kak sreda i sredstvo kommunikacii veka SHekspira). SHekspirovskie chteniya. 2004. [What do the theater trumpets sound about? (Public theater as a medium and means of communication of the age of Shakespeare). Shakespearean readings 2004]. M., Prosvesheniye: 32-49. (in Russian)

4. Naryshkin A.K. Zametki o teatre vremyon Otechestvennoj vojny 1812 goda. [Notes on the theater of the Patriotic war of 1812]. Rezhim dostupa: http://www.museum.ru/museum /1812/Library/Borodino_conf /2013/article43.pdf (in Russian)

5. YAckovskaya I.F. Etapy razvitiya tanca modern i ego stilevoe raznoobrazie. [Stages of development of modern dance and its style diversity]. Kul'tura i obrazovanie. Fevral' 2014. № 2 URL: http://vestnik-rzi.ru/2014/02/1395 (in Russian)

\section{Ссылка для цитирования статьи}

\section{For citation}

Бараниченко Н.В. 2020. Философско-антропологический анализ перформанса в истории европейской цивилизации. NOMOTHETIKA: Философия. Социология. Право. 45 (1): 158-163. DOI 10.18413/2712-746X-2020-45-1-158-163

Baranichenko N.V. 2020. Philosophical-anthropological analysis of performance NOMOTHETIKA: Philosophy. Sociology. Law series. 45 (1): 158-163. (in Russian).

DOI 10.18413/2712-746X-2020-45-1-158-163 